\title{
A Notion of Faces Not Laws: Facebook as Ideological Platform
}

\author{
Matthew Levy
}

In the figure of "Big Brother," George Orwell[1] gives us a generic version of the totalitarian leader-image, the face of an all-seeing state power at once governmental and familial. Big Brother is the big Other personified, a symbol of the power of the state that is specifically not the power of the individual; its design hides the average person's own role in propping up the totalitarian order, while suggesting that the gaze of the state is protective, like that of an older sibling. In Facebook, we have another figure of power, not a single still image but a dynamic and interactive social network of friendly faces. A more subtle but real commercial power interest-rather than that of the state-pervades a collection of overlapping connections: friendly, familial, fraternal, collegial, professional.

In Facebook, the face of Big Brother has been replaced by the actual face of your big brother (sister, in my case). And your work friend. And your college roommate. And that person you had a crush on but never asked out. And that face you cannot place but did not refuse to "friend" because you don't want to hurt anyone's feelings to no purpose. You are watching them and they are watching you and you "like" this and they "like" that and the marketers are watching it all and figuring you out. In the future, your desires will appear before you as options to buy with uncanny speed and accuracy, things you did not even know you wanted and likely do not need: options for identity, channels for communication, venues for community commoditized.

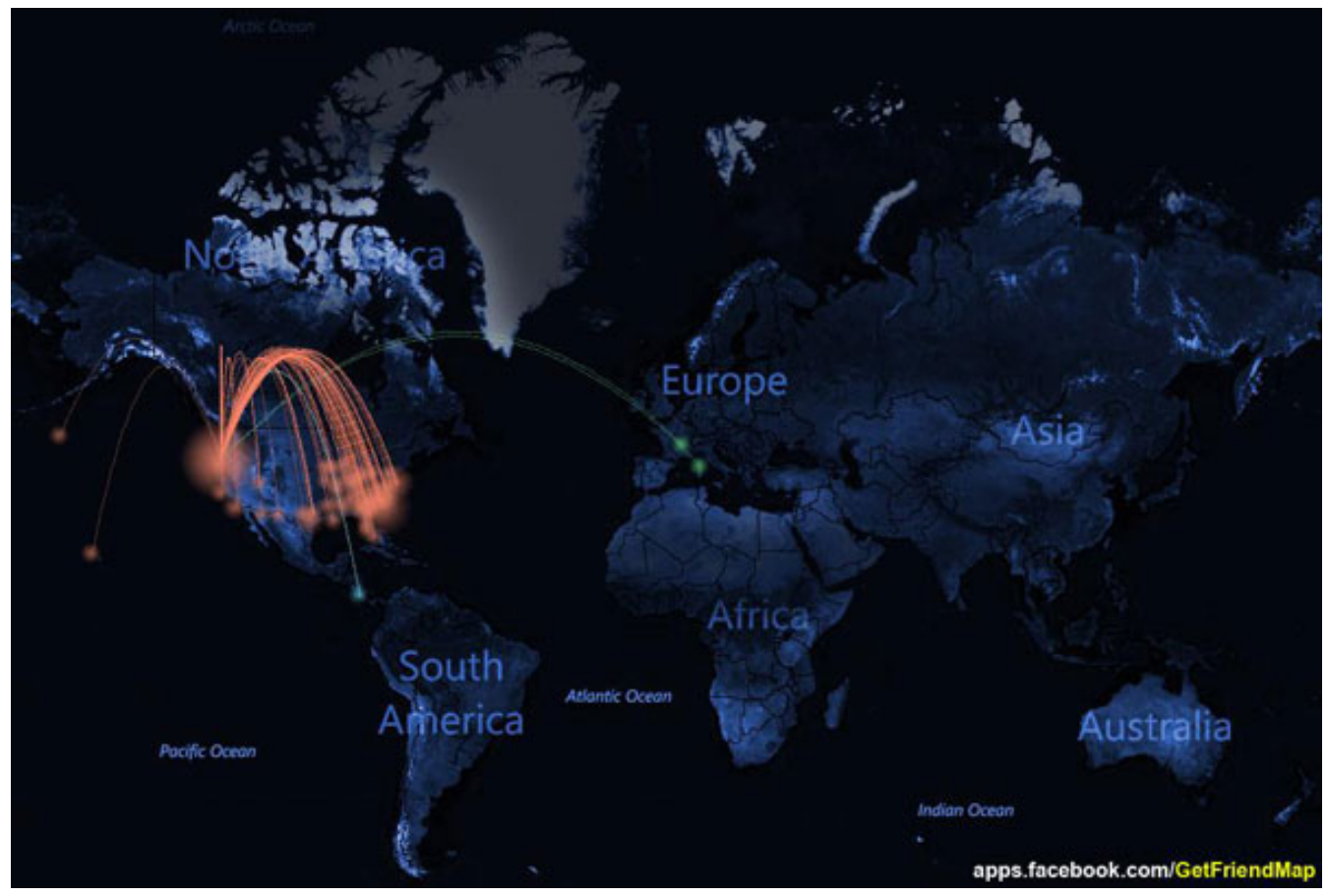




\section{| Digital Disclosure}

I saw a student walking across campus the other day wearing a T-shirt that read, "Got privilege?" Yes, I have always lived as a digital "have." My parents bought a computer when I was very young and I had my own by junior high school. I played my Atari and, for a short period, "visited" online bulletin boards to play the early precursors to today's Massively Multi-Player Online Games. I was formally inducted into the geek elite in 1987 when, to begin my junior year of high school, I moved from my parents' house in Wilmington, North Carolina to the "New Dorm" at the then seven year old North Carolina School of Science and Math. The dorms were not yet networked, but I was assigned an email address usable on the nascent internet. The few times I went to the computer lab to use it, I got my first glimpses of the vanguard of the e-ttached: the small class of people who felt more powerful and self-realized at a slave terminal than in their walking-around reality that they now call IRL, in real life. I overheard them snickering about bombing each other's accounts with automatic spam mailings. I didn't exactly recoil from this expanding virtual life, but I walked away. This was not my crowd, I thought, in a teenage way, oblivious that I was passing up a front row seat and potential role to play in the invention of our future. As awkward as I was, I did not want to mediate my friendships. Face to face still meant sharing space; Skype was science fiction. Over time, the e-ttached class learned marketing and found ways to satisfy the technical and psychological barriers to web use. Computer usage soared and the chiropractors celebrated. The Revenge of the Nerds.

In graduate school, I flirted with the idea of making technology a major part of my intellectual work and identity. I took graduate courses on rhetoric, technology, and the New Economy. I designed academic websites (such as Fastcapitalism) and did a little freelance web work for a dot com startup-can you say "cognitive dissonance"? After I finished my schooling, my interest in technology waned somewhat. I no longer code and I'm no early adapter. This year, I became one of the last people I know to begin text messaging through my phone, when my seventy year old father suggested that I do so. I have thus far successfully ignored the social pressure to Twitter.

I have, though, frittered away hours on Facebook. I have hundreds of "friends," most of whom I can identify if I think hard enough about it. I like to see "where they are now" (when I can remember who they are). I enjoy sharing a new cultural find and benefitting from the discoveries of others: new books, obscure films, recovered videos of favorite musicians on Youtube. Facebook is fun and noisy - a party line. Facebook also has its traps, and investigating these traps is the best way to recognize its true nature. Most users log on to Facebook to network and as a diversion, but Facebook's fundamental purpose is marketing.

I spent about an hour a day for a couple of weeks playing a game on Facebook called City of Wonder. In this game, you grow the population of your city by building houses that produce "people" and then you satisfy the "happiness" needs of people with other "cultural" buildings. To generate "silver" you build yet more buildings that produce various goods. Or you can pay real money with Paypal for "gold." (I am tempted to put "real money" in quotes because all money has a virtual aspect to it, and for the people who play it, even the toy silver has value. Money works because we believe in it, not because of its intrinsic value). The game strikes me as an interesting lesson in economics for a grade school audience. But, as one of my clever students pointed out, these Facebook games are like "the button" from the TV show Lost. You sacrifice your time to the need to click it over and over and you feel a real urgency to do so, but you aren't sure why. It was this student's insight that helped me decide that this experiment had gone on long enough[2]. Was the game named for the fact that it takes a little while for you to Wonder why you are wasting your creative energy helping to build this virtual space?

The most popular game on your Facebook, recently surpassing Farmville, is now another City model called CityVille, which I chose not to play because to even start playing you have to agree to waive privacy rights: to give the game company access to "basic information" ("Includes name, profile picture, gender, networks, user ID, list of friends, and any other information I've shared with everyone.'); the right for the game company to send you email outside of Facebook; and the right for the game to post to your "Wall," which means that the game makes public announcements within your network of friends about your activity. Those permissions have to do with limiting what information Facebook gives to CityVille. This game demands enough information from Facebook to recognize you, to represent you to yourself and other players with the right picture and such, and the right to market itself using your Facebook page. These permissions say nothing about how CityVille will treat information it gets from your activity within its game, the information it doesn't need to request from Facebook but that you give it directly. What you do inside the game... well, that is fair game. If you "drill down" to learn more about the privacy rights, you see that CityVille has been certified with the reassuringly named TRUSTe Privacy Seal. You have to read on to discover that the purpose of this mark is to inspire trust in users. The TRUSTe policy does not indicate that information is 
not shared. To get this mark, the company only needs to communicate whether it shares your information and make a good faith effort to protect your data from unintentional breaches. Furthermore, the privacy policy communicates that the company does share your data with other companies.

In other words, you can trust CityVille not to pretend it won't share your data. If you assume this trust extends to actually keeping your privacy, that assumption is your own silliness at work. At this time, the game is only one month old but already has 61.7 million users. It seems that many Facebookers do not share my concerns about privacy. Facebook and Zynga can fairly claim that they have not shared user information without warning. The precise nature of the door that users have to open in order to let this game in is unclear. From my reading, I have to assume that, other than a reasonable effort not to expose credit card information, there is little protection. After all, the sharing of fungible information is not a minimal necessity; it is the whole point of the platform from the point of view of the service providers. This door would be better described as a network of channels. We may not know for years what rights these millions of users have clicked away for access to a seemingly innocuous diversion, building a virtual toy city.

Hardly an unmitigated evil, Facebook's downsides are easy to ignore-not just the loss of privacy with its open-ended consequences, but also the drawbacks that cynics have warned us about regarding civilization and its technologies for years, such as if when we fail to connect authentically with what and who is near because we are so busy clicking into the void and twittering over distances. Facebook's upsides are obvious. The primary benefit of Facebook is that it offers an easy way to connect and reconnect with family, friends, and acquaintances-often superficially, of course, but not always. I have watched Facebook facilitate a family reunion between the estranged members of the family of someone very near to me. Depending on how it is used, Facebook has the capacity to enrich lives in certain and tangible ways.

As big and cosmopolitan as Facebook is, it has a small town aspect to it. Facebook was modeled on university face books, which were designed for students to get to know each other more easily. Facebook was originally restricted to campuses, and was a way for someone to make friends on campus and, as the film The Social Network emphasizes, a way to get status and get laid. Once Facebook relinquished its exclusivity model by opening to internet users outside of universities, a different set of social concerns came into play. In distinct contrast to some of its precursors (like sexed up MySpace), Facebook is not just a space for peers and most people do not treat it like a fantasy space. Facebookers often "friend" not just their friends but also parents and children, teachers and students, and coworkers of all types. Individuals tend to interact differently with different audiences. Most people say they would tell a story to their parents differently than they would tell a close friend or sibling or people at work. Those who "friend" people from all areas of their lives, though, learn to project a more generic self to Facebook. For many kids, their self-presentation has to be appropriate for peers and parents. For adults, it must cross the personal and professional boundary. And so this image of self is not at all the liberating anonymous self that people used to talk about in connection with cyberspace. Facebook is not a "puppet motel," the name Laurie Anderson used for anonymous chat rooms or virtual spaces where a sleazy atmosphere prevails. The atmosphere of Facebook is playful but also highly constrained by social expectations.

When people deride Facebook, the criticisms are usually not very deeply felt. For instance, people express amazement - in a condescending voice_ - about what others post: "Do they really think we care what they are eating?" But social games and phatic communication do have value. Doesn't friendship and family interaction always entail some degree of patience with, even care for, the banalities of others? The advertisements, well, those we have long been accustomed to. It is easy to disdain the lowest common denominator offerings of commercial culture, which addict us with its junk food and junk thought. The better offerings of commercial culture, like inexpensive novels, affordable basic goods, higher-quality television, and useful "free" websites like Google and Facebook-these are the things that make commercial culture practically impossible to resist.

What distinguishes these games and other interactions from a nice game of Scrabble with friends for me is that they are mediated by a large corporation (beyond the one time purchase of a game). It isn't new for commercials to try to insinuate products into family and other social contexts, but the interactive nature of Facebook makes this insinuation that much more effective. Meeting up in Facebook can be as much like taking frequent trips to a casino as like gathering in a family-owned restaurant or in one's home. As glad as I am for how virtual communities like Facebook facilitate connections with others, these connections also strike me as a consolation prize for the alienation from more authentic forms of community that societal change has brought. I wonder whether these consolations, like prescription drugs, make it more easy for us to endure contemporary social arrangements and estrangements, to be less likely to reach out for the more rewarding interactions that are available, and to be less likely to demand 
rewards that aren't available_-including a more just and humane social order.

And yet, an honest consideration of Facebook requires that we consider both its disadvantages and its advantages: first, how Facebook makes private social interactions public in a way that further privatizes and commodifies social space and the public sphere; second, how Facebook as a figure of the emerging shape of social life is substantially different than the figure of Big Brother, opening up opportunities for real-time cooperation and facilitating the sharing of ideas (and not just to marketers and advertisers).

\section{| Becoming the Tools of our Tools}

During the Clinton presidency, we heard a lot about the digital divide, "haves" and "have nots." Disparities of access to technology (access to access) are a major concern; also of concern is the obligation to use. The cynic Diogenes warned Athenians about dependence on material things as a primary obstacle to self-reliance and true philosophy. We feel this when the power goes out and demands a change in our routine, but the power comes back on and we forget the lesson. We won't soon forget the lesson of the automobile, however. We have built our cities around the automobile and the ideological assumption that we would always be able to move quickly cheaply. Now that the costs have become more obvious, the ideology of car use is written into physical reality. The location of people's homes presents a fairly substantial obstacle between us and a more intelligent arrangement that would require less moving around and make mass transit more functional. On top of the expense of moving homes is people's attachments to them. There you have the cynical critique in a nutshell: There are actual and emotional reasons that people won't live the good life-each new "convenience" adds another so-called reason.

Diogenes' warning, echoed by figures like Henry David Thoreau and Herbert Marcuse, has gained relevance with the passage of time, as technology has crept, then rolled, and then flashed at light speed. Technology is seductive and few have the desire or discipline to do without devices. Elite technologists invent and enjoy disproportionate control over standards and so arguably experience a less alienating relationship to technology. For the rest of us "haves," though, a lingering doubt remains about the effect of technological speedup on our quality of life and our participation as citizens. Being wired (or wireless, for that matter) means being advantageously connected, yes. It also means being "roped in," and not just into that unconvincingly "ergonomic" desk chair.

The traditional cynical solution is to distinguish between needs and wants and to be radically parsimonious about the extras. Diogenes gave up his cup after seeing a boy drink from his hands. Thoreau moved to the woods for a period. Most of us, though, are not ready to make such an experiment, much less to make such a commitment. How does one determine whether a device is a need or a want? It is a question of simplicity, but not a simple question. For my part, I don't expect an opportunity to unplug myself for a period greater than two weeks any time soon. Though my usage is not particularly forward-thinking or extreme, many of my daily rituals involve gadgets. Perhaps not all of my peers would cop to such dependence, but most people I know a generation younger than myself or more would find it at least as difficult to imagine an uncomputed life.

For me, as now for the rapidly-expanding class of wired people, technologies are tools, interfaces, and social spaces. They have become my mainline to writing, in the normal sense of the word, and, also as I think of writing more broadly, as the ongoing, collaborative composition of the social world. Asked to write more than thirty words with pen, I long for a keyboard. Computers have trained me to type, and my hand no longer likes to scribble. As the old cultural ways atrophy and new ways become normal, the implements that support them become cultural fixtures. You can opt out, but to do so means opting out of avenues to community and influence within those communities, which, though we may consider them less authentic, become more central in their cultural importance all the time. Technology has become a major component of my ideology and of most people's, at least in the sense of "ideology" that refers not to a set of opinions but to actual behaviors and rituals that integrate people into social structures. Insofar as electronic devices determine our actual behavior on a day to day basis, it is not too much to say that ideology is engineered.

\section{| Platform as Ideological Support}

John Adams envisioned the United States as a nation of laws, not men. His idea was that legal codes would 
apply to each person equally, not being subject to the whims of powerful individuals, and offer equal protection. There would be no king or Big Brother above the law. There are other codes, though (not legal codes but having legal status as intellectual property) that have increasing influence on the way we live, the shape of community, and the distribution of power. Codes make up the computer applications that we program and that program our lives in turn. It is entirely appropriate that news outlets so closely follow the jockeying between Facebook, Google, and Microsoft, because their market shares dictate their power to construct our technological environment.

Tools meet users halfway. That is to say, the designers make tools and platforms with users in mind, to appeal. Many devices and applications never catch on, and most users will only adjust their behavior to a tool gradually. To be widely adopted, a tool has to have at least some functions that are already in great demand or are easy to learn, intuitive. Once hooked, though, people change their behavior in radical ways in keeping with what their tools — and the changing environment that these tools together represent-have to offer. For instance, the fact that I can access my files from any networked computer changes my relationship to space in real ways. I can work anywhere. The fact that I can text people wherever they are changes my relationship to time. I can alter my plans at a moment's notice. On the other hand, others may now expect me to work everywhere or to change my plans instantly.

The movement from pen to keyboard or from a paper file to an electronic file is not a movement from nature to technology. It is a movement from mechanical technology to electronic technology. Technology is mostly visible when it changes. By those definitions of ideology that see visible options as less ideological and invisible or automatic habits as more ideological, a given piece of technology becomes more ideological as people get used to it as it becomes imbricated with our ways of life. More and more people are developing the skills needed to adapt to new technologies, and effective design makes using new tools more intuitive. As such, part of the dynamic of "fast capitalism" is a new situation in which ideology incorporates change faster. We have choices and purchase new practices from a dizzying array of options; however, as various platforms get more popular, the social pressure increases to text message, Facebook and twitter.

The social pressure to use communication technologies-"You don't have a cellphone?!"-warns against interpreting the availability of consumer choices as a clear avenue to freedom. The fact that control over the development of new technologies is distributed widely through complex economic relationships does not mean there is no coercive element to the adoption of new technoideologies. Is my consent really consent when, with everyone around me participating, it doesn't feel like there are real alternatives? I know that Facebook seeks to exploit my connection to friends and family, but I do it anyway. This is ideological cynicism as defined by Peter Sloterdijk, as when you see something is amiss in your way of living but don't change. It is the polar opposite of Diogenean cynicism, which sought to reject false needs and maximize individual autonomy and intellectual development through a conscious practice of material poverty.

Yet, the speedup of technological change may point to a different sort of ideological dynamic than what Sloterdijk diagnosed, his idea of ideology as cynical intransigence. This other technoideological development, an increased plasticity of ideology, is amoral: computer programming as social programming, e-pedagogy for us all. Pedagogy has always sought to shape practice. Now pedagogy can be designed into virtual and actual environments and updated wirelessly.

I think the word "platform" is helpful when thinking about what it means to think of Facebook as a material, environmental structure of ideology. In politics, "platform" refers to the doctrine of a party; in computing, "platform" refers to a framework for running applications (strictly speaking, a platform goes between an operating system and other applications, so that it doesn't matter if you are surfing the web on a Mac or PC, for instance); in economics, "platform" refers to a device that mediates between suppliers and consumers (television mediates between advertisers and viewers; credit cards mediate between cardholders and merchants). Facebook provides platforms in only the latter two senses. It is not a political platform, but that doesn't mean that its platforms are not politically significant. Facebook and its applications facilitate and encourage networking within and between people of all political mindsets, but they are nevertheless ideological, because they mediate and channel our actions and interactions. Facebook's platform bypasses the pesky obstacles of opinion and reflection. It influences behaviors directly, supporting certain kinds of habits (linking, status updating, gaming) and mediating between consumers and marketers.

Another platform would be the Amazon website, which is primarily an interface between a seller and its customers, and secondarily a place for people to share their opinions about products (a "consumer community"). Facebook, by contrast, seems on the surface to be primarily designed to encourage interactions between friends, but the bottomline purpose of Facebook is like that of commercial television: to create a platform connecting people and marketing 
agents. The great advance of Facebook from a marketing standbook is that its friendly networking context creates an environment in which users readily reveal information that can inform marketing efforts. Advertisements update in real time based upon what users do and say; beyond this, marketers can use the information they gather to make all kinds of decisions about future products and marketing efforts.

Facebook-native games allow you to buy your "friends" virtual objects. You can pay with real money or fake money that it takes time to accumulate, in which case you are paying with your attention to advertisements. As described above, these applications often require that you give access to personal information in order to play them. Facebook has claimed that unless users specifically give this permission, its automated triggering of advertisement does not also give "partners" information about the practices of individuals. This claim has not gone unchallenged. There are suits pending in Rhode Island regarding a series of privacy breaches against Facebook and Zynga, the creator of its most popular games [3]. And even when users are given the opportunity to deny permission to share information, they seem to assume very readily that giving permission will be harmless.

\section{| The Bearable Lightness of Relationship Marketing}

Facebook is not just a real platform. It is also a figure for all of the various social networks and commercial mechanisms that teach us to channel our self expression in ways that benefit the efficiency of marketing, that teach us to see our purchases and commercial affiliations as signs of identity (Mac, Windows, or Linux?; iPhone or Blackberry?; Farmville or CityVille?) and make us more accustomed to marketing surveillance (like the "savings clubs" in the supermarket that track our purchases). Our willing participation in market research has made capitalism incredibly responsive to consumer desire. Based upon what you choose, it anticipates what you might want and strikes preemptively. Every time Facebook shows me someone I may know (because we have "friends" in common) or Amazon alerts me to a new translation by an author whose works I have purchased in the past, I have reason to be glad they are watching. Each little reward makes me that much less likely to regard all this watching as intrusive. The friendliness of commercial surveillance lowers my guard. Why should I worry for my freedom? This isn't Nineteen Eighty-Four and it isn't the government watching me. Yet, isn't this lack of concern for commercial surveillance consonant with the quiet acceptance of the Patriot Act with its expensive and (I would argue) unconstitutional gathering of information without probable cause?

In the transition from Big Brother to Facebook, the experience of control is transformed. Big Brother announces itself as a coercive top-down force bent on criminalizing pleasure and creativity. Big Brother is dark, a figure of the new dark age, with its medievalesque repression of sexuality and free thought. Facebook-or more precisely the economic social order of which Facebook represents an example and for which Facebook provides a perfect figure-is all light: a mirthful celebration of individuality and expression. "Light" can also describe the relationship to consequences we experience in Facebook. The commercial purpose of Facebook as a medium is overshadowed by the social messages of its participants. Users feel the social consequences of Facebook far more immediately than its economic ones. If you post something that offends your friends on Facebook, you can experience social consequences, and I would not want to deny that these consequences are actual. Yet, we hardly see these consequences as consequences of the medium. We think of them as relationships between individuals. The figure of Big Brother is a dark, imposing presence that announces its control over relationships. Facebook is a bright, facilitating presence, which wins adherents by making its ideological function as subtle as possible.

Describing Facebook's efforts to surpass Google in the area of email by making the technology of messaging quicker and less obtrusive, Andrew Bosworth, the director of engineering at Facebook, has said, "The future of messaging is more real time, more conversational and more casual.... The medium isn't the message. The message is the message." It was Marshall McLuhan's message that the way we communicate has societal effects over and above the content of individual communications. It is no surprise that the message Facebook wants to send is opposite to McLuhan's warning. It is helpful to Facebook's effort to use social networking to facilitate marketing that we do not reflect upon the impacts of the medium, that we readily relinquish our privacy rights in order to play a game we know nothing about.

In Nineteen Eighty-Four, resistance to Big Brother is real because it is risky. Saying "no" to Facebook is an "unbearably light" act. You can say, "I don't Facebook because I don't have time" and the most you risk is mild mocking and fewer invitations to social events. If you say, "I don't do Facebook because it represents yet another 
way that the mighty profit motive, the root of all evil, the love of money, binds itself into our lives," your political pretensions may be mocked, but still the Thought Police will not break down your door. The genius of Facebook and its analogues is this: If, after a time on Facebook, you decide that having your friendships commercialized is distasteful and decide to destroy your account, this act will not be seen as a rejection of technology-dependence or commercialism, it will be seen as a withdrawal from community and a rejection of friends.

\section{The Compromises of Cynicism}

The tradition of cynicism has been prophetic in its description of how our vision of the good can by narrowed by dependence on material goods. Yet, cynicism has usually been an experiment rather than a complete commitment. According to anecdotes, Diogenes refused certain conveniences as a rhetorical act that communicated his objections to the cultural assumptions and practices at the core of the Athenian way of life. Yet, Diogenes also chose to live in Athens off of its excesses. He did not reject Athens completely by leaving. His philosophy was a way of living better within the city. Likewise, Thoreau's experiment in Walden was incomplete. He did not live permanently in the cabin he built there. He took a break from his periods of isolation by visiting his mother, who did his laundry. Cynical experiments have deep significance for modern life, in which technological speedup continues to mediate our social lives in deeper and deeper ways; however, it would be easy to overestimate the degree to which experiments in disimbrication can release us from our social nature. Their examples inspire us to give serious reconsideration of which of our apparent needs may actually be dubious wants in disguise and whether the values of our culture are as healthy as they could be; however, neither Diogenes nor Thoreau gave us reason to believe that a complete escape from social demands is the path to Enlightenment for the individual or even a real possibility. In fact, there is at times a distinctly anti-social quality to the behavior of the great cynics, whether it is wanking in the agora or refusing to pay taxes. Such gestures are hardly simple to evaluate. When social life crushes the individual or maintains more than one set of standards, as in a nation of men not laws, it is oppressive; however, the ideology of the individual with its debt to the cynical tradition can also threaten more authentic forms of community involvement. I think of the contemporary Tea Party, which seems unable to distinguish the rights of individuals from the power of corporations, paranoid regarding state power but blind to the abuses of Capital.

I hope I have made clear my misgivings about the rising dominance of Facebook due to how it commercializes our actual practices (our very lives) and gives corporations even more personal information that can be used to manipulate us, to further confuse our needs and wants. Unlike medieval religion and the system in Nineteen EightyFour, commercial culture does not control us by telling us our desires are base; rather, it satisfies every desire that it profitably can, relieving some of the frustration that might lead us to demand a better order. Big Brother subordinates the individual to the group through suppression; social networking achieves the same result through appeasement and flattery. At the same time, I see that the same interactive nature that makes our imbrications with things complete also opens up increased opportunities for cooperation and sharing of ideas. We should not dismiss too quickly what opportunities platforms like Facebook may offer. Can't we also find some hope in the ascendance of a cultural figure that celebrates both the individual and the social? Can we see each person's Facebook page as a leaf of grass, as in Walt Whitman's metaphor for democratic community? Can Facebook help us sing the body electric? Or is it yet another mechanism by which we indebt ourselves to the company store?

Far from being threatened by information, Facebook profits off the rapid and unimpeded flow of messages. The profit motive still operates, to be sure, but its impact on the content is not the same as in previous platforms like television. Facebook isn't neutral in terms of form - the medium favors shorter messages and videos and addicting games-but it is far more neutral in terms of the opinions contained within the messages. Facebook behavior, make no mistake, is ideological behavior; that behavior is more directly guided by engineering than ever before, bypassing for the most part the complicating factor of opinion. The content of your thoughts while you Facebook do not need to align with any particular perspective; so long as you keep participating, almost any content will do as matter to mine for marketers. The source of messages is no longer centralized and the efficiency of the system means that smaller audiences are viable sources of profit to keep the system running. Because it profits through its ability to move messages cheaply and wants to move more and more without regard for the content, users legitimately enjoy more control over what information is passed. In this sense, Facebook is more democratic than, say, a movie studio, which has to be rather selective about what kinds of cultural productions it promotes because of the expense of 
production. This excessive quality of content opens up a significant degree of democracy in the sharing of ideas.

I shared Thanksgiving with my family at the California home of my sister, an hour north of Los Angeles, where my cousin Gina works as a documentary filmmaker. After telling me about her latest project, The 6th Extinction [4], she asked me what I was writing, and I gave her my cynical take on Facebook. Given the fact that her project explores the thesis that there are too many human beings on the planet and that we are causing a mass extinction on par with the other five mass extinctions that have occurred in the last five million years, I expected her to be more negative about Facebook, which is itself a great energy-sucking behemoth. She brought to the issue, though, the perspective of a documentary filmmaker who does not make Hollywood blockbusters, for whom funding is always an issue, and for whom social networking provides a great opportunity to reach out to supporters.

I was already somewhat familiar with this concept of "crowd financing" or "crowdfunding" because I have been a member for four years of Kiva.org, a social networking website that allows you to make no-interest microloans. Gina gave me the links to a couple of similar sites that are designed to help film makers get funding, IndieGoGo and Kickstarter. Filmmakers use Facebook to create a social network of supporters and people with relevant concerns, which they can then refer over to the crowd-financing sites when they have a project in development. People give money because they like the filmmakers, appreciate their work, or want to help bring attention to an issue they care about. This provides an example of how social networking can support collective action in a way that raises the level of discourse. A film does not have to be profitable or find a wealthy patron to get made if its social value can be made evident to enough people. Facebook is, at its core, a marketing platform, but one with democratic potential that can be turned to creative, beneficial use.

Big Brother is a single, gloom-stricken face demanding devotion and submission. It is a symbol of the totalitarian state's false promise to care for its citizens. In Facebook, we see our own friendly faces represented alongside those of others to whom we are already devoted (to some degree). The figure of Facebook suggests a state of freedom facilitated by consumer capitalism. This "freedom" is neither as false and oppressive as that in Nineteen EightyFour nor as uncompromised as pro-capitalism types tend to assume. I don't use Big Brother as a foil to Facebook in order to suggest that we should regard social networks as totalitarian or that we should reject them altogether in the tradition of ethical cynicism. Facebooking can be made to serve higher ends, but this mode of use is not the default. Facebook is not Big Brother, but as with Big Brother, it is designed for us but not primarily for our benefit. What is true about capitalism in general is true about Facebook, the vanguard of its ideological support. The most fervent supporters of capitalism defend lightly-regulated markets by comparing the social system they have helped create to totalitarian, so-called communist societies, as if the big political question has only one answer out of two possibilities. This is, of course, a false choice. Just because we are not enslaved to a false god like Big Brother or Stalin does not mean that we are realizing our power in the best possible way.

\section{Endnotes}

1. Thank you Becky Scarborough for your papers on Orwell in my Critical Theory class that got me thinking about the contemporary meaning of the figure of Big Brother.

2. Thank you to Daniel Landon for this clever observation.

3. "Facebook and Zynga Face Lawsuits over Privacy Breach," Wall Street Journal. October 19, 2002. Online. http://blogs.wsj.com/digits/2010/10/19/facebookand-zynga-face-lawsuits-over-privacy-breach/

4. http://6thextinctiondoc.com/ 